\title{
Surfatron-Produced Atmospheric-Pressure Plasma Jet Applied to Candida Biofilms
}

\author{
A.C.O.C. Doria,,${ }^{a,}$ F.R. Figueira, ${ }^{a}$ J.S.B. Lima, ${ }^{b}$ H.S. Maciel, ${ }^{c}$ S. Khouri, ${ }^{a}$ \\ \& S. Pessoac \\ aUniversidade do Vale do Paraíba/IP\&D/Laboratório de Biotecnologia e Plasmas Elétricos, \\ São José dos Campos, SP, 12244-000, Brazil; 'Universidade de Taubaté/Departamento de \\ Engenharia Mecânica, Taubaté, SP, 12060-440, Brazil; 'Centro de Ciência e Tecnologia de \\ Plasmas e Materiais-PlasMat/Instituto Tecnológico de Aeronáutica, São José dos Campos, SP, \\ 12228-900, Brazil \\ *Address all correspondence to: Anelise Cristina Osório Cesar Doria, Universidade do Vale do Paraíba/IP\&D/ \\ Laboratório de Biotecnologia e Plasmas Elétricos, São José dos Campos, SP, 12244-000, Brazil; \\ Tel.: +55 15 39471142, E-mail: ane.doria@gmail.com
}

\begin{abstract}
Fungal biofilms represent a constant and predominant cause of chronic infections. They exhibit increased tolerance to antifungal agents and immunological variations, making them difficult to treat with conventional therapeutic agents. The technology of nonthermal plasmas at atmospheric pressure has been increasingly used in studies aimed at eradication and control of fungal contamination. Here, we evaluate the action of a plasma jet that is generated by a surfatron source, using different gas compositions on polyurethane (PU) samples that are contaminated with biofilms of Candida albicans and Candida parapsilosis. Samples were treated using plasma with 4 standard liters per minute (SLM) argon + 6 SLM air in $100 \mathrm{~W}$ of applied power (group 1), 4 SLM argon + 9 SLM argon with water vapor in $50 \mathrm{~W}$ (group 2), and 4 SLM argon + 9 SLM argon with water vapor in $150 \mathrm{~W}$ (group 3 ). We performed treatments in the postdischarge region $(30 \mathrm{~mm})$ for $10 \mathrm{~min}$. We characterized plasmas using optical emission spectroscopy and scanning electron microscopy on samples by infrared images of the surface during plasma treatment, determining colony-forming units (CFU) and surface morphology. Results showed that for $C$. albicans, groups 1 and 3 plasmas were reduced by $100 \%$, whereas for $C$. parapsilosis, groups 2 and 3 showed reductions of $92.41 \%$ and $97.85 \% \mathrm{CFU} / \mathrm{mL}$, respectively. Morphological changes were observed in the biofilm cells, and thermal analyses of substrate surface showed that process parameters were adequate to control Candida contamination, because parameters resulted in a small increase in PU surface temperature $\left(<40^{\circ} \mathrm{C}\right)$ during sterilization.
\end{abstract}

KEY WORDS: atmospheric plasma jet, surfatron, water vapor, argon, Candida albicans, Candida parapsilosis, plasma sterilization

\section{INTRODUCTION}

Candida yeasts are the fourth most-frequent cause of hospital infections worldwide. Considered as commensals in humans, they can lead to opportunistic infections in the growing population of immunocompromised patients. ${ }^{1}$ Such infections are often associated with formation of biofilms, which makes them difficult to treat, contributing to alarming mortality rates. ${ }^{2}$

Biofilm formation can occur on a wide variety of surfaces, including living tissue, medical devices, drinking-water systems, etc. ${ }^{3}$ Such formation impacts the pharmaceutical and 
food industries, environment, and medical and dental care, among others. Adhesion and biofilm formation in medical devices is a serious public health problem. In recent decades, the incidence of microbial infections associated with biofilms has reached $65 \%$ of all cases. ${ }^{4}$ Biofilm formation gives microorganisms greater protection against host immune defenses and antimicrobial action, ultimately favoring establishment of pathogenic processes. ${ }^{5}$

Due to the medical importance of controlling these microorganisms, use of new technologies is necessary. Nonthermal electrical plasmas operated at atmospheric pressure $(\sim 101 \mathrm{kPa})$ are gaining attention as a potential approach to eradicate and control bacterial or fungal infection and/or contamination..$^{6-8}$ As an antimicrobial strategy, advantages of nonthermal plasmas operated at atmospheric pressure include simple design, low construction/operation costs, use of nontoxic gases, gas conditions at or near ambient temperature, and absence of harmful residues. ${ }^{6-8}$ Efficacy is attributed to plasma-derived products such as reactive oxygen species (ROS), reactive nitrogen species (RNS), ultraviolet (UV) radiation, and charged particles. ${ }^{7,9,10}$ The exact mechanism of inactivation is not well elucidated, but hypotheses converge on the importance of ROS and RNS in vital physiological microorganism processes. At low doses, reactive species act to promote cell survival, proliferation, and migration. At high doses, they cause oxidative stress that is related to cellular aging, initiation, and execution of apoptosis. ${ }^{9}$ Much effort and progress has been made in recent years to elucidate exact mechanisms that lead to bacterial or fungal inactivation by the action of electric plasma. ${ }^{8,11-15}$

Several geometries generate nonthermal plasmas at atmospheric pressure, namely, corona discharge, dielectric barrier discharge, microplasmas, and plasma jets. Among discharge geometries for generating plasma jets, we mention here surface wave-sustained discharge. The advantages of using this type of discharge are high plasma density and rapid treatment capabilities in a postdischarge environment, resulting in a wide range of processing applications such as thin-film deposition, gas decontamination, plasma sterilization, light sources and lasers, particle production, and material processing. ${ }^{16}$ Hnilica et al. presented results of polyamide 12 surface treatment using a microwave plasma jet, operating in argon at atmospheric pressure. ${ }^{17}$ The authors observed that plasma treatment of polyamide to improve surface wettability was quite rapid $(25 \mathrm{~ms}) .{ }^{17}$ In another work, Hnilica et al. used an atmospheric-pressure surfatron plasma jet to perform surface treatment of silicon, polyamide, and wood. Some results show a fairly fast treatment time, probably due to high-power density in the surfatron device. ${ }^{18}$ In relation to microbiological studies, Hury et al. reported on inactivation of spores that were exposed in $\mathrm{Ar} / \mathrm{O}_{2}$ microwave-sustained plasmas at low pressures. ${ }^{19}$ Ricard and Monna used microwave $\mathrm{N}_{2} / \mathrm{O}_{2}$ that flowed postdischarge for Escherichia coli inactivation. ${ }^{20}$ Straňák et al. reported on bactericidal effects of $\mathrm{Ar} / \mathrm{O}_{2}$ and $\mathrm{Ar} / \mathrm{N}_{2}$ microwave discharges under open atmosphere on bactericidal cultures Neisseria sicca, Deinococcus radiodurans, Enterococcus feacium, and Stenotrophomonas maltophilia. ${ }^{21}$ This latest work presents possibilities for a surfatron plasma jet source. In the majority of works that use microwave sources for applications in thermosensitive substrates, sources remain under low pressure. Thus, further research is needed on possibilities for this type of plasma source, especially for microbial inactivation. 
In this work, we present results on inactivation of Candida albicans and Candida parapsilosis biofilms that are grown on a polyurethane (PU) substrate by atmospheric surfatron plasma jet, with mixtures of argon, air, and water vapor. The motivation for the use of PU material is its application as the main constituent of the central venous catheter, whose traditional methods of sterilization cannot be used, and so this type of biomedical device gets discarded. Herein, we perform characterization of plasmas using optical emission spectroscopy (OES) and scanning electron microscopy (SEM) on samples of infrared (IR) surface images during plasma treatment, determining colonyforming units (CFU) and surface morphology.

\section{EXPERIMENT}

We prepared fungal suspensions of standard strains of American Type Culture Collection (Manassas, VA) C. albicans (10231) and C. parapsilosis (22019) at a concentration of $10^{6}$ $\mathrm{CFU} / \mathrm{mL}$ in Sabouraud Dextrose Broth (Difco; Sparks, MD USA). Under sterile conditions, we inserted PU plates (3R Plásticos; São Paulo, SP, Brazil) measuring $2 \mathrm{~mm}$ thick and 2 $\mathrm{cm}^{2}$ in area. Samples were then incubated for $48 \mathrm{~h}$ at $37^{\circ} \mathrm{C}$ under constant agitation $(110$ rpm) in an incubator shaker (Marconi MA 420; Piracicaba, SP, Brazil) and then washed with phosphate-buffered saline (PBS) at a $\mathrm{pH}$ of $7.2 \pm 0.1$ to remove nonadherent cells. ${ }^{22}$

Figure 1 shows the experimental setup. Treatment of the contaminated PU surface was carried out using an atmospheric-pressure microwave electrode-free jet-surfatron (Sairem; Neyron, France). Surfatron design consists of a coaxial resonant cavity with a narrow gap around a discharge tube that is located in the center of the surfatron. Surface wave discharge is produced by applying high-frequency electric field (that is intensified by a narrow slit) to gas that is flowing in the discharge tube. The discharge tube was made of quartz, with an inner diameter of $4 \mathrm{~mm}$ and an outer diameter of $6 \mathrm{~mm}$. The end of the discharge tube was $30 \mathrm{~cm}$ from the launching gap. The system was cooled with compressed air during treatments to maintain the integrity of the quartz tube and to avoid overheating the thermosensitive samples. IR images (IR camera model TiS 10, Fluke; Everett, WA USA) evaluated substrate heating during treatment. In this study, we used different flow rates of argon (99.95\% purity) and/or air that were supplied by a medical/ orthodontic compressor (Schulz MSV6-30; Joinville, SC, Brazil) to generate the plasma jet. Rotameters controlled gas flow rate (measured in standard liters per minute [SLM]). To intercalate water vapor into plasma, we inserted argon using another gas line in a flask

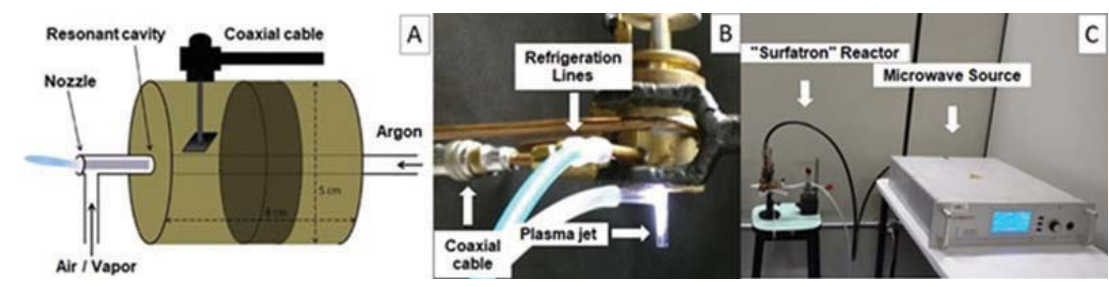

FIG. 1: (A) Surfatron reactor scheme; (B) image of the system in operation; (C) experimental setup

Volume 8, Issue 4, 2018 
containing liquid water, for which the outlet was connected to the perpendicular quartz tube external connection, as shown in Fig. 2. Experiments were performed with applied power that ranged from 50 to $150 \mathrm{~W}$ at atmospheric pressure. Treatments were performed for $10 \mathrm{~min}$ at a distance of $30 \mathrm{~mm}$ between sample and end of the quartz tube. All experiments were performed in triplicate, and samples were divided by plasma process parameters (Table 1).

We used OES to determine optimal plasma conditions for treatment and to investigate plasma species in a UV-visible range of $200-340 \mathrm{~nm}$. We used an Acton Spectra Pro SP-2500i monochromator with a Pixis 256 charge-coupled device camera (Princeton Instruments; Trenton, NJ), which allowed resolution of $0.05 \mathrm{~nm}$. The optical spectrum was obtained using a Lightfield program. This allows determination of integration time for composing the spectrum that is then displayed on a computer screen.

After treatment, we detached sample biofilm plaques in PBS using a vortex stirrer (AP56 Phoenix Luferco; Araraquara, SP, Brazil). We plated $100 \mu \mathrm{L}$ of the control group inoculum and that of the treated groups on Sabouraud agar and incubated for $48 \mathrm{~h}$ at $37^{\circ} \mathrm{C}$, after which $\mathrm{CFU} / \mathrm{mL}$ counts were performed. Results are expressed as percentages of reduction of colony number after treatment, with respect to initial number before treatment. ${ }^{22}$

We then interpreted results by calculating percentage of reduction in number of colonies after treatment versus number of control colonies, considered to be $100 \%{ }^{22} \mathrm{~A}$ statistical analysis was performed using an analysis of variance (ANOVA), followed by application of a post hoc test (Tukey's multiple comparison test) to compare treatment groups against the negative control. We considered a level of $5 \%$ to be significant $(p<$

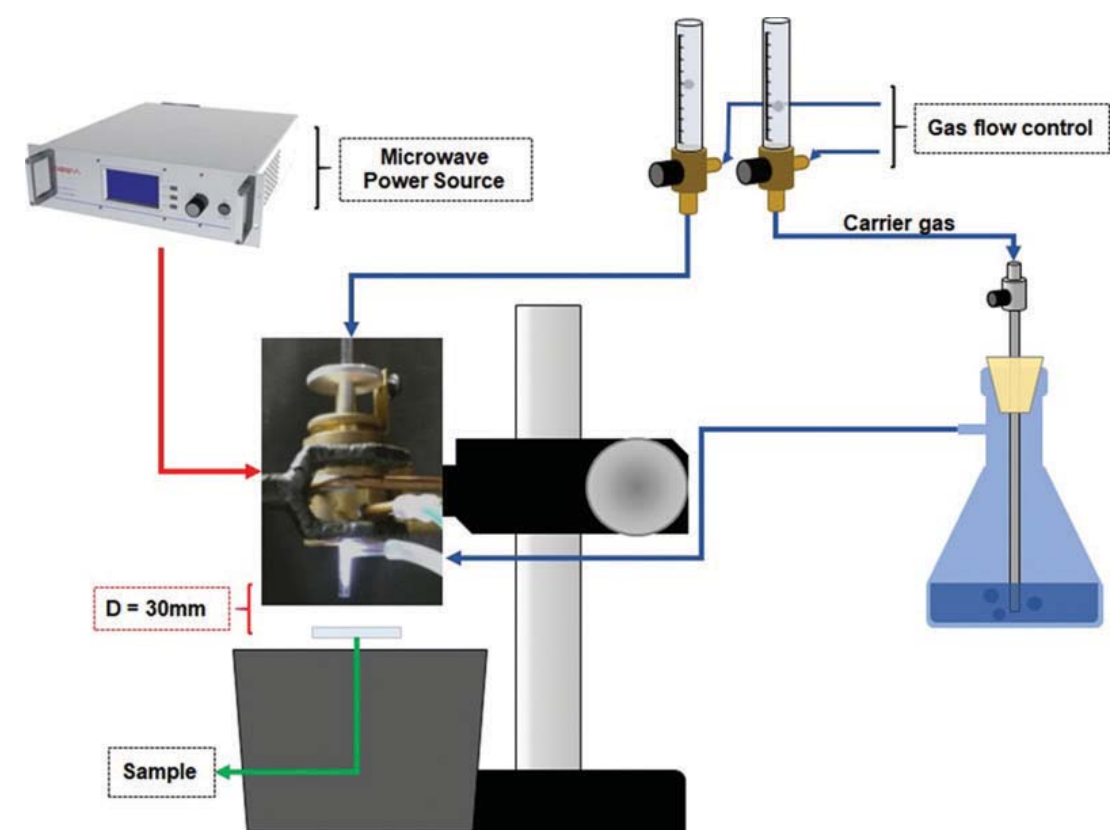

FIG. 2: Water-vapor carrier apparatus; experimental scheme 
TABLE 1: Experimental groups

\begin{tabular}{|c|l|c|}
\hline Group & Gas composition & Power (W) \\
\hline A & Untreated (control) & - \\
\hline B & 4 SLM argon + 6 SLM air & 100 \\
\hline C & 4 SLM argon + 9 SLM argon with water vapor & 50 \\
\hline D & 4 SLM argon + 9 SLM argon with water vapor & 150 \\
\hline
\end{tabular}

0.05). We used SEM model EVO MA 10 (Zeiss; Oberkochen, Germany) to collect micrographs of cells/hyphaes on samples before and after plasma treatment.

\section{RESULTS AND DISCUSSION}

Before performing treatment of PU samples contaminated with Candida spp., we performed OES analyses to establish optimized treatment conditions. Figure 3 presents optical emission spectra in the UV range for plasmas generated in the surfatron reactor, at different values of microwave power, for pure argon gas and its mixtures with air and water vapor. The proportion of 6:4 for the air:argon mixture originates from our previous study. ${ }^{22}$ Optical spectra for pure argon plasma generated in the surfatron reactor for microwave powers of 25, 50, 100, and $150 \mathrm{~W}$ are shown in Fig. 3(a). A greater number of bands and peaks can be noted at wavelengths $<300 \mathrm{~nm}$ (UVC range), corresponding to $\mathrm{NO}$ and $\mathrm{OH}$ radicals. Many of these species arise when microwave power is $>100$ W. In addition, we observed that most UVC radiations (especially $\mathrm{NO}_{\beta}$ ) originate from inside the surfatron cavity. Relative to the main $\mathrm{OH}$ peaks (between 305 and $310 \mathrm{~nm}$ ), an increase in peak intensity by $>1.5 \times$ was observed when plasma was operated at $150 \mathrm{~W}$. The opposite occurred when air was mixed with argon in the proportion of 6:4 in a total flow of 10 SLM (Fig. 3[b]). In this case, OH intensity was high but contained a smaller amount of reactive species compared to pure argon gas. This may be due to the reduction in $\operatorname{argon}$ flow.

Figure 3(c) presents optical spectra for argon/water vapor plasma generated in the surfatron reactor for microwave power of 25, 50, 100, and $150 \mathrm{~W}$. In Fig. 3(c), we see a drastic increase in $\mathrm{OH}$ intensity with increasing plasma power. Thus, higher plasma power for the argon/water vapor mixture could be interesting for treatment of Candida spp.-contaminated surfaces. An outstanding case in Fig. 3(c) is the marked increase in the band between 250 and $260 \mathrm{~nm}$, referring to the band $\mathrm{NO}\left(\mathrm{A}^{2} \Sigma^{+} \rightarrow \mathrm{X}^{2} \Pi\right)$ for $150 \mathrm{~W}$. In this condition, $\mathrm{OH}$ intensity is reduced compared to that for the condition at $100 \mathrm{~W}$. Additional studies are needed to understand this change in plasma chemistry.

Figure 4 presents IR images of sample surfaces during treatment after $180 \mathrm{~s}$. Thermal images show that the substrate temperature did not exceed $37^{\circ} \mathrm{C}$ for the investigated experimental conditions. These results demonstrate that heating of the substrate, which could cause inactivation of the microorganism, was not observed.

Volume 8, Issue 4, 2018 

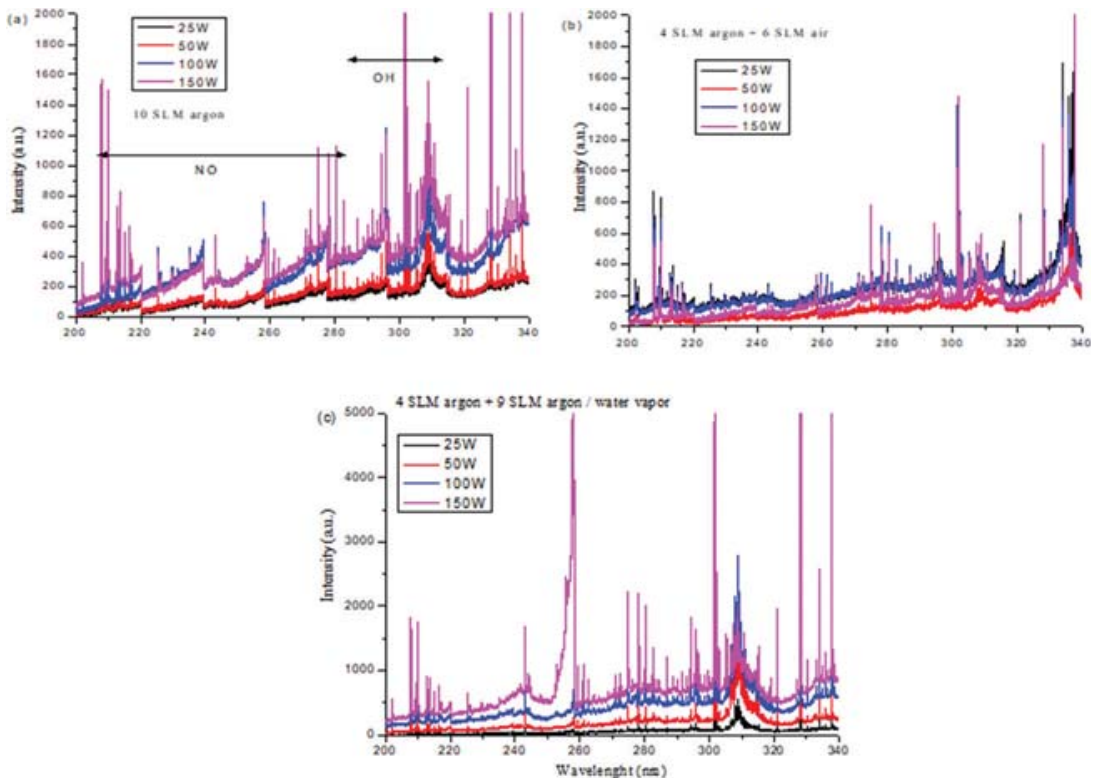

FIG. 3: Optical emission spectra in the UV range for plasmas generated in the surfatron reactor at different values of microwave power for gases argon (a), argon + air (b), and argon + water vapor $(\mathrm{c})$

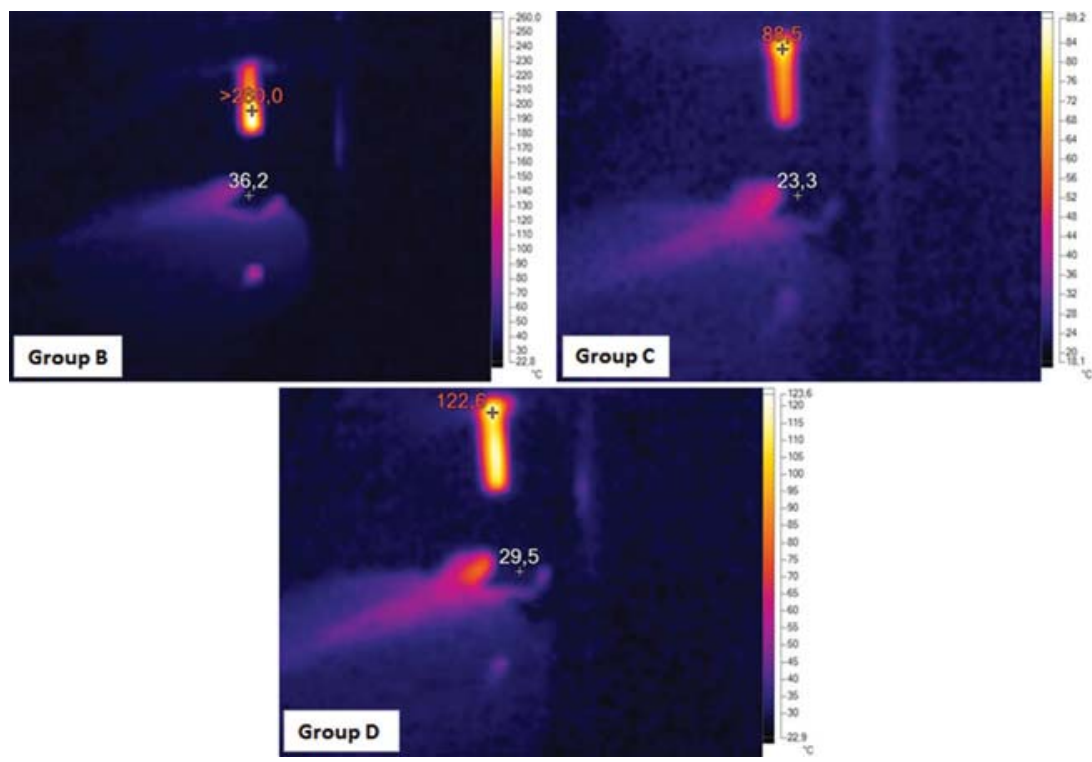

FIG. 4: IR images of sample surfaces during treatment. Group B: 4 SLM argon + 6 SLM air, discharge power $=100 \mathrm{~W}$; group C: 4 SLM argon +9 SLM argon with water vapor, power $=50$ $\mathrm{W}$; and group D: 4 SLM argon + 9 SLM argon with water vapor, power $=150 \mathrm{~W}$ 
Figure 5 shows the box plot for $\mathrm{CFU} / \mathrm{mL}$ values for all studied groups. In addition, Table 2 presents the percentage of reduction in CFU/mL of Candida spp. after plasma exposure. It is possible to visualize, through the results in Fig. 5 and Table 2, that treatments using the surfatron system showed promise for contamination control of both evaluated microorganisms, and the greatest reduction occurred in C. albicans, reaching $100 \%$. However, it should be noted that for the two microorganisms, treatment conditions showed reductions of $\sim 80 \%$, such as those for group $\mathrm{C}$ for $C$. albicans and group B for C. parapsilosis, which presented a higher distribution of results and a lower percentage of reduction $(\sim 79.76 \%$ and $81.54 \%$, respectively). In a study using the same plasma system in water contaminated with strains of $E$. coli, Judée et al. obtained a reduction of $97.67 \%$ after $300 \mathrm{~s}$ of treatment with argon plasma and also confirmed the role of photons that were emitted (mainly by UVC radiation) in antibacterial efficiency of the plasma jet. ${ }^{23}$ In another study using the surfatron system in Gram-positive (E. feacium and S. maltophilia) and Gram-negative ( $N$. sicca and D. radiodurans) bacteria for up to 8 min with-
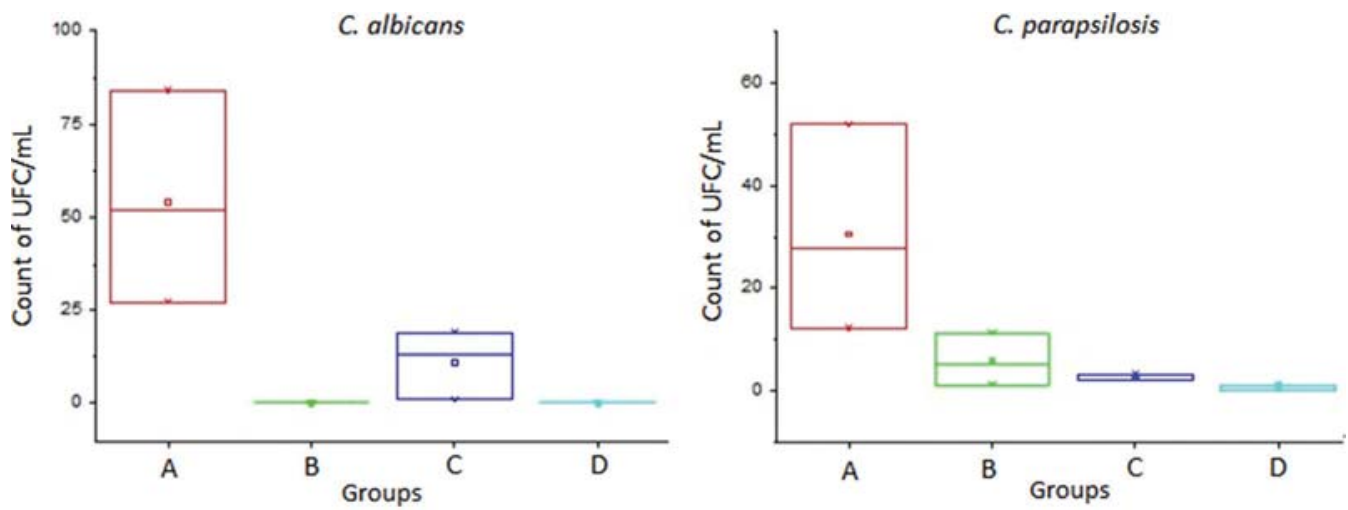

FIG. 5: Dispersion and distribution of CFU/mL counts of control (group A); plasma-treated group at 4 SLM argon + 6 SLM air, discharge power $=100 \mathrm{~W}$ (group B); 4 SLM argon + 9 SLM argon with water vapor, discharge power $=50 \mathrm{~W}$ (group C); and 4 SLM argon + 9 SLM argon with water vapor, discharge power $=150 \mathrm{~W}$ (group D)

TABLE 2: Percentage of CFU $/ \mathrm{mL}$ reduction of Candida spp. after plasma exposure

\begin{tabular}{|c|c|c|}
\hline \multicolumn{3}{|c|}{ Reduction (\%) } \\
\hline Group & C. albicans & C. parapsilosis \\
\hline A & - & - \\
\hline B & 100.00 & 81.54 \\
\hline C & 79.76 & 92.41 \\
\hline D & 100.00 & 97.85 \\
\hline
\end{tabular}

$\mathrm{CFU} / \mathrm{mL}$, colony-forming units per milliliter.

Volume 8, Issue 4, 2018 
$\mathrm{cAr} / \mathrm{O}_{2}$ or $\mathrm{Ar} / \mathrm{N}_{2}$ plasma, and evaluating the inhibition zone formed after treatment and due to incubation, we did not obtain any inhibition for E. feacium and found $176 \mathrm{~mm}^{2}$ of inhibition zone area for $\mathrm{Ar} / \mathrm{O}_{2}$-treated $S$. maltophilia (and this was the composition with better results). ${ }^{21}$ Moreau et al. achieved total inactivation of Bacillus subtilis spores in 40 min with power of $100 \mathrm{~W}$, using a gas mixture in the proportion of $2 \% \mathrm{O}_{2} / 98 \% \mathrm{~N}_{2}{ }^{24} \mathrm{~A}$ comparison of results with groups $\mathrm{B}$ and $\mathrm{C}$ showed that increasing discharge power during treatment improved the percentage of reduction of CFU, but consumption of argon gas was higher and not of interest for possible large-scale application. Thus, the best gas composition is that of group B, because when adding air with argon, the amounts of ROS and RNS increase. On the other hand, when analyzing results in relation to reduction of contamination by species of Candida sp., we must consider that species differentiation is in the morphological and physiological characteristics (biochemical reactions) and the capacity of biofilm and extracellular matrix formation. These genus differences justify the variation in CFU reduction percentages and demonstrate the difficulty of creating a unique methodology for all species. There is even greater difficulty when creating for different types of microorganisms of clinical interest. ${ }^{25,26}$

In addition, results in Fig. 5 were verified by means of ANOVA and Tukey's test (Table 3). When comparing values obtained in groups treated with their respective control groups, all results were statistically significant, except for $C$. parapsilosis treated with 4 SLM argon + 6 SLM air at $100 \mathrm{~W}$ (group B).

Figure 6 shows SEM micrographs of the control and groups treated with plasma surfatron. In all of the micrographs, we can see the presence of Candida spp. contamination. In the micrographs of the plasma-treated groups, occurrence of structural morphological alterations was verified, with some cells presenting irregularities or volumetric deformation, and others appeared to have been lysed or even completely devoid of structure, forming a "mass."

\section{CONCLUSION}

This study investigated the action of plasma jet generated by a surfatron source using three different gas compositions on PU samples contaminated with biofilms of $C$.

TABLE 3: Comparison between treated groups and control with $5 \%$ significance level using Tukey's test

\begin{tabular}{|c|c|c|c|}
\hline Microorganism & Comparison between groups & Standard error & Value $(\boldsymbol{p})$ \\
\hline \multirow{3}{*}{ C. albicans } & $\mathrm{A}$ and B & 12.24972 & 0.00939 \\
\cline { 2 - 4 } & $\mathrm{A}$ and C & 12.24972 & 0.0313 \\
\cline { 2 - 4 } & $\mathrm{A}$ and D & 12.24972 & 0.00939 \\
\hline \multirow{3}{*}{ C. parapsilosis } & $\mathrm{A}$ and B & 8.47873 & 0.07153 \\
\cline { 2 - 4 } & $\mathrm{A}$ and C & 8.47873 & 0.04112 \\
\cline { 2 - 4 } & $\mathrm{A}$ and D & 8.47873 & 0.03127 \\
\hline
\end{tabular}




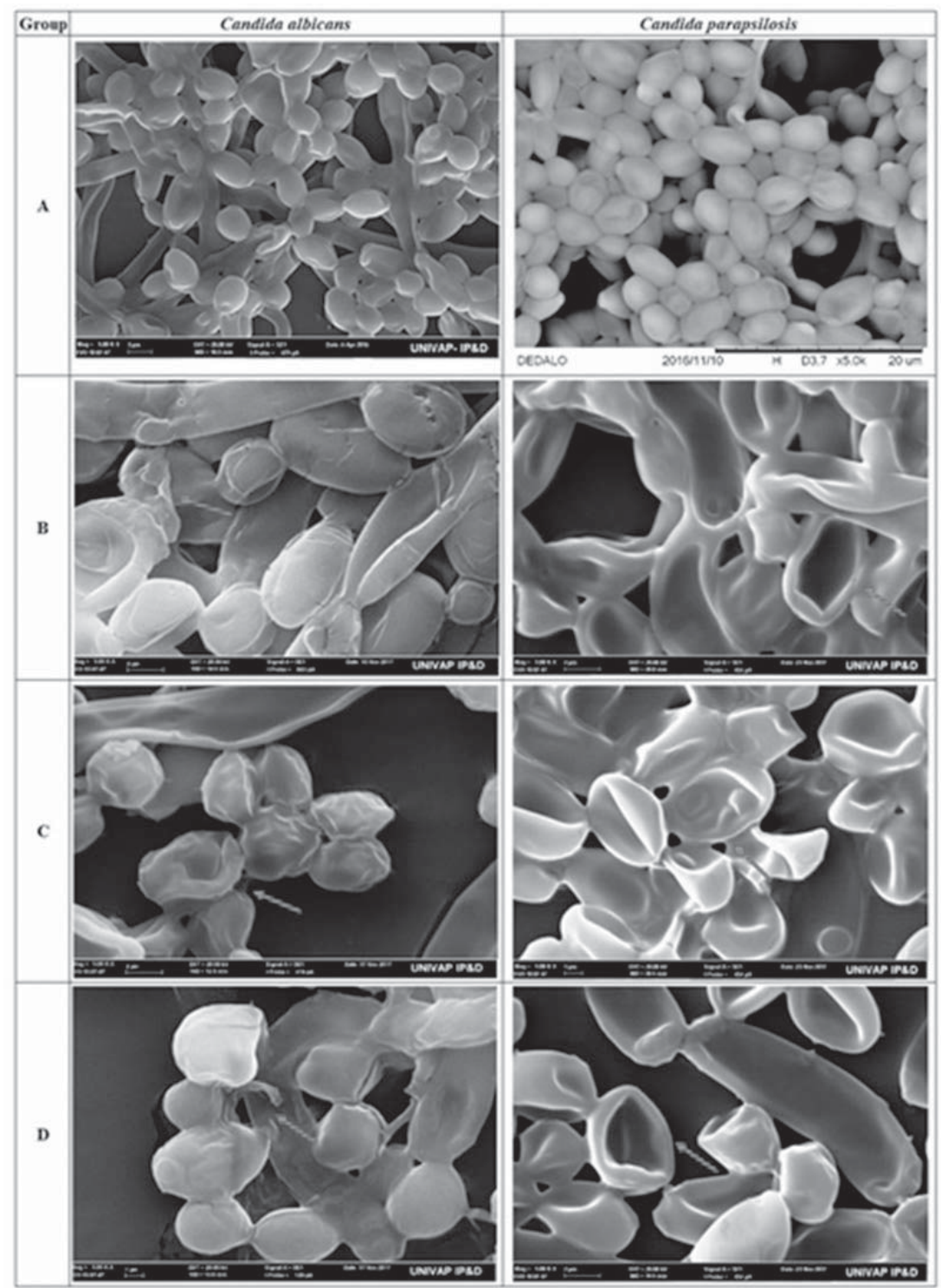

FIG. 6: SEM micrographs of all four groups and samples before and after treatment

albicans and C. parapsilosis. Results show that treatment parameters were efficient to reduce contamination, except in the group of $C$. parapsilosis treated with 4 SLM argon +6 SLM air at $100 \mathrm{~W}$, which presented no statistically significant difference as compared to the control group. SEM micrographs confirm the presence of biofilm in all samples and suggest some morphological changes in cells after treatment, but these findings are not conclusive, because the technique is qualitative. IR images did not 
show significant heating in the samples during treatment, discarding a thermal effect for inactivation of biofilms.

\section{ACKNOWEDGMENTS}

This work was supported by the São Paulo Research Foundation (FAPESP) grants No. 2011/50773-0, No. 2015/10876-6 and No. 2018/01265-1) and by the Coordenação de Aperfeiçoamento de Pessoal de Nível Superior - Brasil (CAPES) - Finance Code 001.

\section{REFERENCES}

1. Doria ACOC, Figueira FR, Lima JSB, Maciel HS, Khouri S, Pessoa RS. Sterilization of Candida albicans biofilms grown on polymers by atmospheric plasma: From plasma devices to biofilm analysis. In: Henderson J, editor. Biofilms characterization, applications and recent advances. Hauppauge, NY: Nova Science Publications, Inc.; 2016.

2. Pierce CG, Chaturvedi AK, Lazzell AL, Powell AT, Saville SP, McHardy SF, Lopez-Ribot JL. A novel small molecule inhibitor of Candida albicans biofilm formation, filamentation and virulence with low potential for the development of resistance. NPJ Biofilms Microbiomes [serial on the Internet]. 2015 Aug 12;1:15012. Available from: http://www.nature.com/article/articles/npjbiofims 201512 .

3. Kaali P, Strmberg E, Karlsso S. Prevention of biofilm associated infections and degradation of polymeric materials used in biomedical applications. In: Laskovski AN, editor. Biomedical engineering, trends in materials science. InTech [serial on the Internet]. 2011. [27 p.]. Available from: http://www. intechopen.com/books/biomedical-engineering-trends-in-materials-science/prevention-of-biofilmassociated-infections-and-degradation-of-polymeric-materials-used-in-biomedica.

4. Santana DP, Ribeiro EL, Menezes ACS, Naves PLF. Novas abordagens sobre os fatores de virulência de Candida albicans. Rev Ciências Médicas E Biológicas. 2013;12(2):229-33.

5. Soll DR. Candida biofilms: Is adhesion sexy? Curr Biol. 2008 Aug;18(16):R717-20.

6. Gaunt LF, Beggs CB, Georghiou GE. Bactericidal action of the reactive species produced by gasdischarge nonthermal plasma at atmospheric pressure: A review. IEEE Trans Plasma Sci. 2006;34(4 II): $1257-69$.

7. Kong MG, Kroesen G, Morfill G, Nosenko T, Shimizu T, Van Dijk J, Zimmermann JL. Plasma medicine: An introductory review. New J Phys. 2009;11:1-35.

8. Laroussi M. Nonthermal decontamination of biological media by atmospheric-pressure plasmas: Review, analysis, and prospects. IEEE Trans Plasma Sci. 2002;30(4 I):1409-15.

9. Arjunan KP, Sharma VK, Ptasinska S. Effects of atmospheric pressure plasmas on isolated and cellular DNA - A review. Int J Mol Sci. 2015;16(2):2971-3016.

10. Napp J, Daeschlein G, Napp M, von Podewils S, Gümbel D, Spitzmueller R, Fornaciari P, Hinz P, Jünger M. On the history of plasma treatment and comparison of microbiostatic efficacy of a historical high-frequency plasma device with two modern devices. GMS Hyg Infect Control [Internet]. 2015;10:Doc08. Available from: http://www.ncbi.nlm.nih.gov/pubmed/26124985.

11. Alkawareek MY, Algwari QT, Gorman SP, Graham WG, O'Connell D, Gilmore BF. Application of atmospheric pressure nonthermal plasma for the in vitro eradication of bacterial biofilms. FEMS Immunol Med Microbiol. 2012 Jul;65(2):381-4

12. Chen C, Liu DX, Liu ZC, Yang AJ, Chen HL, Shama G, Kong MG. A model of plasma-biofilm and plasma-tissue interactions at ambient pressure. Plasma Chem Plasma Proc. 2014 May 4;34(3):403-41.

13. Mai-Prochnow A, Murphy AB, McLean KM, Kong MG, Ostrikov K. Atmospheric pressure plasmas: Infection control and bacterial responses. Int J Antimicrob Agents. 2014 Jun;43(6):508-17. 
14. Taghizadeh L, Brackman G, Nikiforov A, van der Mullen J, Leys C, Coenye T. Inactivation of biofilms using a low power atmospheric pressure argon plasma jet: The role of entrained nitrogen. Plasma Proc Polym. 2015 Jan;12(1):75-81.

15. Traba C, Liang JF. The inactivation of Staphylococcus aureus biofilms using low-power argon plasma in a layer-by-layer approach. Biofouling. 2015 Jan 2;31(1):39-48.

16. Hamdan A, Liu J-L, Cha MS. Microwave plasma jet in water: Characterization and feasibility to wastewater treatment. Plasma Chem Plasma Process [Internet]. 2018 Jul 6. Available from: http:// link.springer.com/10.1007/s11090-018-9918-y.

17. Hnilica J, Potočňáková L, Stupavská M, Kudrle V. Rapid surface treatment of polyamide 12 by microwave plasma jet. Appl Surf Sci. 2014 Jan;288:251-7.

18. Hnilica J, Kudrle V, Potocnakova L. Surface treatment by atmospheric-pressure surfatron jet. IEEE Trans Plasma Sci. 2012 Nov;40(11):2925-30.

19. Hury S, Vidal DR, Desor F, Pelletier L. A parametric study of the destruction efficiency of Bacillus spores in low pressure oxygen-based plasmas. Lett Appl Microbiol. 1998 Jun;26(6):417-21.

20. Ricard A, Monna V. Reactive molecular plasmas. Plasma Sources Sci Technol. 2002 Aug 1;11(3A):A150-3.

21. Straňák V, Tichý M, Kř́ha V, Scholtz V, Šerá B, Špatenka P. Technological applications of surfatron produced discharge. J Optoelectron Adv Mater. 2007;9(4):852-7.

22. Doria ACOC, Sorge CDPC, Santos TB, Brandão J, Gonçalves PAR, Maciel HS, Khouri S, Pessoa RS. Application of post-discharge region of atmospheric pressure argon and air plasma jet in the contamination control of Candida albicans biofilms. Res Biomed Eng. 2015 Dec;31(4):358-62.

23. Judée F, Wattieaux G, Merbahi N, Mansour M, Castanié-Cornet MP. The antibacterial activity of a microwave argon plasma jet at atmospheric pressure relies mainly on UV-C radiations. J Phys D Appl Phys. 2014;47(40):405201.

24. Moreau S, Moisan M, Tabrizian M, Barbeau J, Pelletier J, Ricard A, Yahia L'H. Using the flowing afterglow of a plasma to inactivate Bacillus subtilis spores: Influence of the operating conditions. J Appl Phys. 2000;88(2):1166-74.

25. Gomez JE, Sockalingum GD, Aubert D, Toubas D, Pinon JM, Witthuhn FMM. Characterisation of Candida reference strains by ATR-FTIR. In: Greve J, Puppels GJ, Otto C, Boston DI, London I, editors. Spectroscopy of biological molecules: New directions. The Netherlands: Enschede; 1999; pp. 469-70.

26. Cavalheiro M, Teixeira MC. Candida biofilms: Threats, challenges, and promising strategies. Front Med [Internet]. 2018 Feb 13;5. Available from: http://journal.frontiersin.org/article/10.3389/ fmed.2018.00028/full.

Volume 8, Issue 4, 2018 
